\title{
USING MODIS AEROSOL OPTICAL DEPTH TO PREDICT PM10 OVER AL AIN REGION, UAE
}

\author{
N. Saleous ${ }^{1}$, S. Issa ${ }^{2, *}$, M. Alsuwaidi ${ }^{1}$ \\ ${ }^{1}$ Dept. of Geography, College of Humanities and Social Sciences, UAEU, Al Ain, UAE - nazmi.saleous@uaeu.ac.ae \\ ${ }^{2}$ Dept. of Geology, College of Science, UAEU, Al Ain, UAE - salem.essa@uaeu.ac.ae
}

Commission III, WG III/8

KEY WORDS: Air quality, Particulate matter, Aerosol optical depth, MODIS, regression, UAE.

\begin{abstract}
:
PM10 concentrations are essential for assessing air quality in arid areas. They are usually measured at air quality monitoring stations. The limited number of monitoring stations can make difficult to study significantly the spatial variability of PM10 over relatively large areas. This study aimed at evaluating the use of Aerosol Optical Depth derived from satellite data to estimate PM10 concentrations. The continuous coverage offered by remote sensing data helps to address the limitation encountered with the spatial distribution of relevant monitoring stations. In the current study we compared MODIS AOD at 550nm included in MCD19A2 and we established a regression equation between AOD and PM10. The use of daily AOD at $1 \mathrm{~km}$ resolution helped establish regression with acceptable correlation coefficient. The regression equation is then used to create daily maps of estimated PM10 concentrations over the study area and helped assessing their variability.
\end{abstract}

\section{INTRODUCTION}

\subsection{Overview}

Air pollution has always been considered a major problem worldwide particularly in areas with high population concentrations, areas with strong industrial activities and within arid and semi-arid regions in particular. The formation of such air pollutants depends upon the sources of their precursors whether natural or anthropogenic. The level of air pollution is derived from measured concentrations of present pollutants that usually include $\mathrm{O}_{3}, \mathrm{NO}_{2}$ and particulate matter (PM). This latter is measured for particulates with aerodynamic diameter less than $2.5 \mu \mathrm{m}$ or less than $10 \mu \mathrm{m}$ and are denoted respectively PM2.5 and PM10. Many studies established a strong relationship between the concentrations of PM2.5 and PM10 on one hand and respiratory diseases on the other (Liu, 2009). Contributors to PM in the atmosphere include many sources such as construction sites crushing or grinding operations, dust mobilized by vehicles on roads and meteorological factors such as fog and fumes. The challenges of meeting air quality standards in any region are impacted by identifying theses sources and further identifying the trans-borders transport of these pollutants.

Furthermore, air pollutants express a wide range of spatiotemporal variations in any one region making it difficult to properly model and predict (Omari et. al., 2019). Identifying the spatiotemporal distribution of PM would help in the assessment of the population levels of exposure and significantly aid in identifying the sources and formation of air pollutants in the area.

While PM concentrations are measured using ground based instruments at air quality monitoring stations, remote sensing can provide a means to extend the estimation of PM concentrations beyond monitoring stations to wider areas. Many researchers focused on estimating PM2.5 or PM10 from aerosol optical depth (AOD) retrieved from satellite imagery. This study aims at developing statistical correlation models between AOD derived from remote sensing data and PM10 over Al Ain city region in the United Arab Emirates (UAE). Several AOD global products exist and are of particular interest for this study. However, we opted to use only the $1 \mathrm{KM}$ AOD provided in the Moderate Resolution Imaging Spectroradiometer (MODIS) Multi-Angle Implementation of Atmospheric Correction (MAIAC) product (MCD19A2) as it is produced on daily basis at a higher spatial resolution than other available products.

\subsection{Background}

Particulate matter (PM) is one of the major air quality issues in the world these days. Exposure to tiny particles with diameter size smaller than $10 \mu \mathrm{m}$ can cause respiratory problems and lead to premature death (Villeneuve et al., 2002). Air quality assessment of PM is typically supported by measurement data from established ground monitoring stations. However, these stations do not provide an adequate spatial coverage to meet the needs of mapping regional air quality and human exposure assessments since they are considered as point measurements (Tian and Chen, 2010). Even though satellite measurements are less accurate than ground-based measurements, AOD retrieved from satellite sensors is considered as a good proxy for ground discovered PM mass concentrations and a valuable tool for monitoring aerosol pollution (Koelemeijer et al., 2006). MODIS provides a daily basis distribution of AOD near-globally with spatial resolution of $1 \mathrm{~km}$ over both ocean and land. While PM is derived from ground measurements as the daily average of dry mass concentration at the surface, AOD represents the columnar aerosol loading from the surface to the top of the atmosphere (Engel-Cox et al., 2004). The relationship between these two variables relies on a number of factors, including aerosol type and its chemical composition, aerosol vertical distribution, as well as its spatial and temporal variability, 
which are controlled by spatio-temporal distribution of emissions and meteorological conditions (Chu et al., 2003).

During the last decade, numerous studies have analyzed the relationship between PM and AOD. Earlier studies reported a large range of correlation coefficients $(\mathrm{R})$ for univariate linear regression models (UV) for different cities around the world. For instance, a study of PM2.5-AOD relationship over the whole USA, including 1300 ground observation stations, found non-uniform correlations across USA, being strongest within the northeast part of USA ( $\mathrm{R}>0.8)$ and weakest within the north-western part of USA ( $\mathrm{R}<0.2)$, with an average of 0.43 over the whole area (Engel-Cox et al., 2004). For 26 cities around the world (in Australia, India, USA, Hong Kong and Switzerland), the correlation ranged from 0.11 to 0.85 (Gupta et al., 2006). Even though AOD and daily averaged 24-hour PM10 derived from the Aerosol Robotic Network (AERONET) correlate well for some areas in specific situations with stable meteorological conditions and fixed pollution sources, most of those studies concluded that AOD alone does not universally represent surface PM concentrations well, since other factors have an effect on the PM-AOD relationship like aerosol type and chemical composition, the vertical distribution of aerosols, its temporal variability and meteorological parameters (Chu et al., 2003).

Moreover, satellites can measure almost the same columnar AOD throughout two different conditions: first with low planetary boundary layer height (PBLH) when the surface PM concentrations can be high and second with high (PBLH) when surface concentrations are low (Gupta and Christopher S, 2009). Ground and spaceborne lidars, like Cloud Aerosol and Infrared Pathfinder Satellite Observation (CALIPSO) provide information on vertical distribution of aerosols that may facilitate the assessment of whether aerosols are restricted to the surface planetary boundary layer (PBL) or aloft (Engel-Cox et al., 2006). Additionally, lidar apportionment of the fraction of aerosol optical depth that is within the PBL can be scaled to give better agreement with PM that come from the surface than does the total column amount (Engel-Cox et al., 2004). However, there are limitations with these data since CALIPSO provides observations with a very narrow swath and the global coverage is reached only after many weeks. These data can be useful for improvement and interpretation of the PM-AOD relationship by searching the most significant upper-level transport events. However, they cannot be used for spatial mapping of daily averaged PM concentrations. Note that some studies using limited observations of vertical distribution of aerosols from lidars have concluded that aerosols are well mixed and mostly confined within the PBL (Gupta and Christopher, 2009).

The PM-AOD relationship can also be affected by certain meteorological parameters including: humidity, due to hygroscopic growth of particles and production of secondary particles, temperature, due to effect on photochemical reactions in which PM particles are produced, wind speed, that influences horizontal and vertical dispersion and temperature vertical gradients that affect vertical mixing (Gupta and Christopher, 2009).

Even though the satellite-based retrieval of air quality is promising, it poses several challenges. There are several factors that affect the relationship between AOD and PM10. For instance, the satellite-derived quantities provide columnar information for ambient conditions while the PM10 measurements are representative of near-surface dry mass concentrations. The satellite footprints represent large spatial areas and are subject to cloud contamination (Zhang et al., 2005). Other issues including variations in aerosol type and hygroscopicity must be adequately understood before using satellite data for air quality assessment. In the present study MODIS-derived AOD at $1 \mathrm{Km}$ from two satellites, Terra and Aqua, is compared with the several ground monitoring stations PM10 mass concentrations $\left(\mu \mathrm{g} / \mathrm{m}^{3}\right)$ spread over AL Ain region by developing statistical correlation and regression models to allow the prediction of PM10 over the study area.

\section{METHODOLOGY}

\subsection{Study area}

The study area, shown in figure 1, covers AL Ain region extending from $(24.55 \mathrm{~N}, 55.30 \mathrm{E})$ to $(23.33 \mathrm{~N}, 55.80 \mathrm{E})$ and is located in the eastern part of the UAE. The study area falls in a desert climate zone with scarce precipitation. It is dominated by sand dunes and sand sheets with some date palm farms and urban centres. The dominancy of sand and sand dunes in the study area makes it exposed to major dust outbreaks affecting significantly air quality.

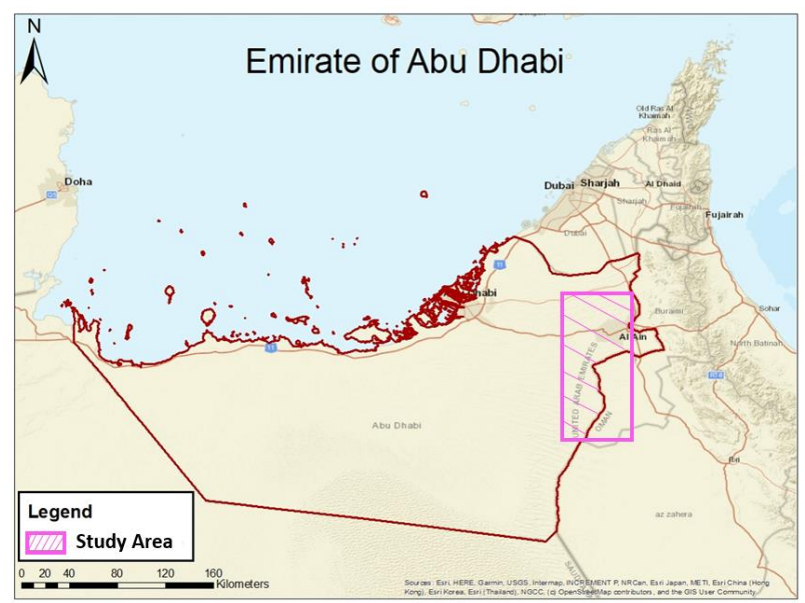

Figure 1. Study area.

\subsection{Data}

PM10 data is collected continuously by Abu Dhabi Environment Agency (EAD) at five air quality monitoring stations inside the study area. These stations are listed along with their coordinates and land use type in table 1 . The daily average of PM10 is made available and is used in the World Air Quality Index Projects (aqicn.org). In this study, we use the daily PM10 average expressed in $\mu \mathrm{g} / \mathrm{m}^{3}$ collected in 2018 .

\begin{tabular}{|l|c|c|c|}
\hline Station & Latitude & Longitude & Area Type \\
\hline AL Ain Islamic & 24.219058 & 55.734864 & Urban \\
Institute & & & \\
AL Ain Street & 24.225858 & 55.765831 & Urban traffic \\
Sweihan & 24.46666 & 55.342883 & Suburban \\
AL Tawia & 24.259183 & 55.704869 & Suburban \\
Zakher & 24.163467 & 55.702106 & Urban \\
AL Qua'a & 23.531154 & 55.48596 & Rural \\
\hline
\end{tabular}

Table 1. Air monitoring stations in the study area.

The remote sensing derived aerosol loading used in this study is provided by AOD at $550 \mathrm{~nm}$ included in the MODIS MCD19A2 product. The MAIAC algorithm used in this product was developed for AOD retrieval over both bright and dark surfaces from MODIS data at $1 \mathrm{~km}$ resolution (Lyapustin et al., 
2011). The algorithm uses time series analysis based on spectral regressions in the blue $(0.47 \mathrm{~mm})$ and shortwave infrared $(2.1$ $\mathrm{mm}$ ) bands considering the bidirectional properties of surface reflectance. AOD retrieval using this approach assumes that surface reflectance remains stable considering a time series of 16 days. This is true in arid regions where land cover is almost the same throughout the year. MCD19A2 data can be freely accessed via NASA LAADS DAAC website (https://ladsweb.modaps.eosdis.nasa.gov). Daily MCD19A2 collected in 2018 for tile h26v3, that encompasses our study area, is downloaded and used in this study.

\subsection{Methods}

The processing approach is summarized in figure 2. Subsets of the study area for 2018 are extracted from the downloaded MCD19A2 tiles using the HDF-EOS to GeoTIFF Conversion Tool (HEG) (https://lpdaac.usgs.gov/tools/heg/). Pixels corresponding to the location of the air quality monitoring stations are then identified and values of AOD at 550nm for these pixels are extracted for all days in 2018 and stored in a CSV file. Microsoft Excel is then used to study the relation between measured PM10 concentrations and corresponding AOD values and to establish a regression equation. This latter is evaluated and then applied to MODIS AOD data to create raster images of PM10 estimates at $1 \mathrm{~km}$ spatial resolution for the whole study area.

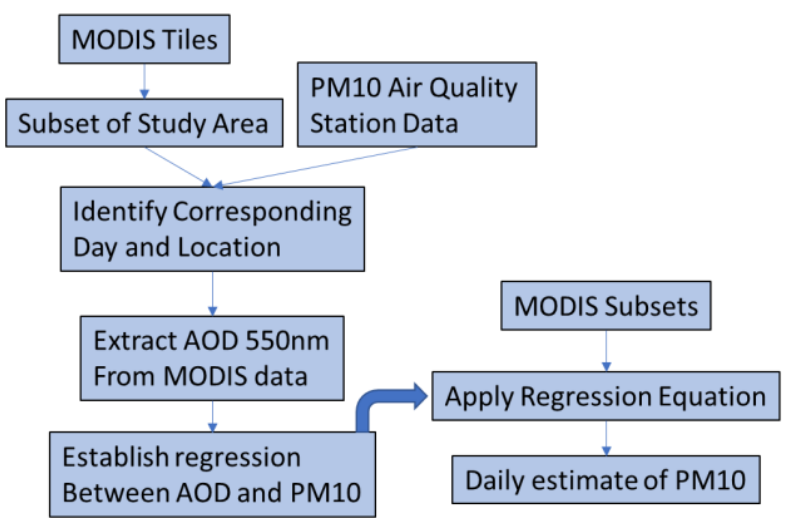

Figure 2. Processing approach.

\section{RESULTS AND DISCUSSION}

\subsection{PM10 concentrations}

The average daily analysis of the PM10 concentrations derived from the monitoring stations is depicted in Figure 3. It shows that the study area has moderate levels of PM10 with comparable average values across the five stations ranging from $120-158 \mu \mathrm{g} / \mathrm{m}^{3}$.

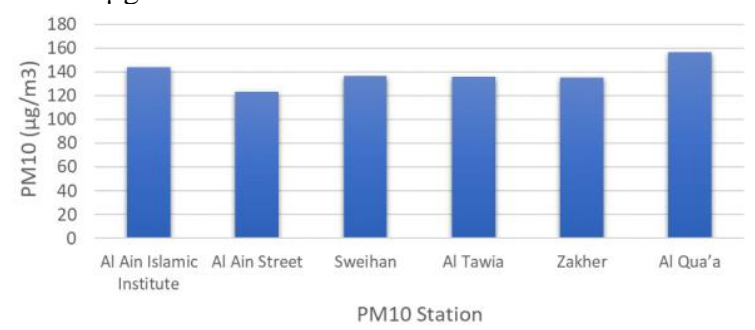

Figure 3. Average daily concentrations of measured PM10.
The average monthly PM10 concentration for 2018 is shown in figure 4. It is noticeable that Al Ain City has the largest PM10 concentration in July, reaching $290 \mu \mathrm{g} / \mathrm{m} 3$. The figure shows a slight decrease of PM10 concentration from January to March, followed by an increase that becomes sharp after April to reach a peak in July where it starts decreasing again. These variations seem to coincide with seasonality in UAE where two seasons are mainly distinguished: winter from November to April and summer from May to October. Desert storms activities peak in the months of July and August increasing significantly PM10 concentrations.

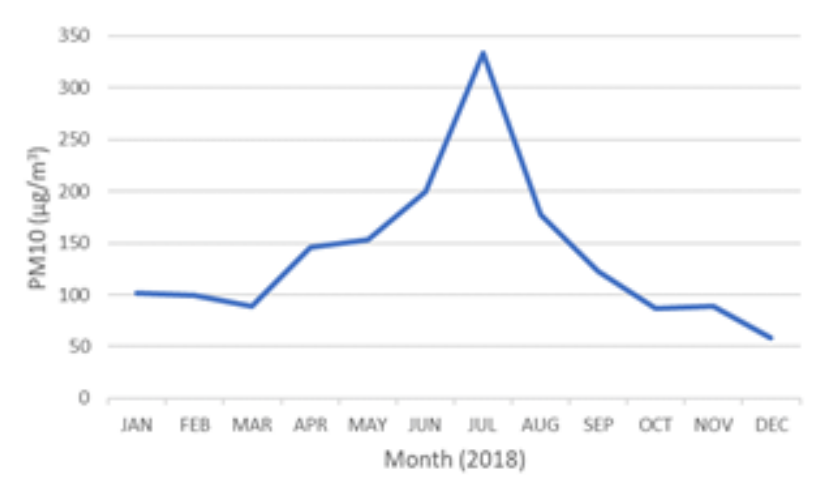

Figure 4. Monthly average PM10 concentrations.

\subsection{MODIS AOD}

Figure 5 shows the average monthly AOD obtained from the MODIS MCD19A2 product over the study area for in 2018. As with PM10 measurements, MODIS AOD is high during the summer period. The highest values of were observed in the June-August period where sand storms are most active.

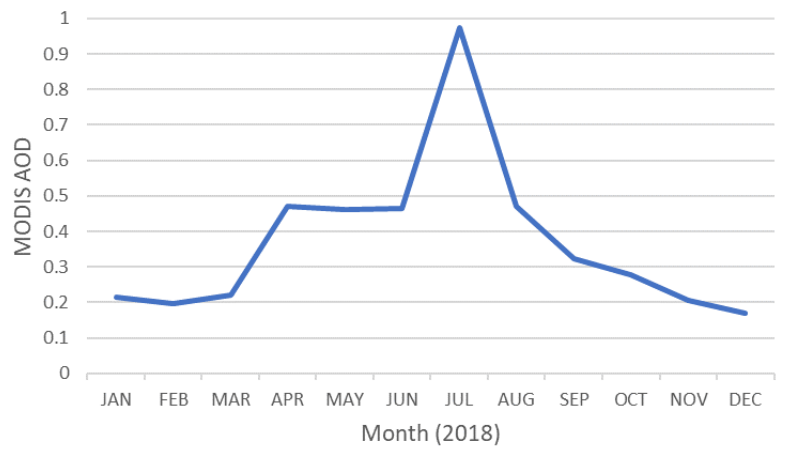

Figure 5. Monthly average of MCD19A2 AOD over the study area in 2018.

\subsection{Correlation between AOD and PM10 concentration}

MODIS AOD values observed in pixels matching the location of the five monitoring stations were extracted and exported to a spreadsheet for 2018. These values were then used to compare the measured PM10 concentrations using regression analysis. Figure 6 depicts the regression analysis performed for each monitoring station individually. A linear regression with acceptable $\mathrm{R}^{2}$ value ranging between 0.67 and 0.72 was obtained for all stations. The best correlation was observed in the rural area of Al Qua'a. 
Al Ain Islamic Institute Station
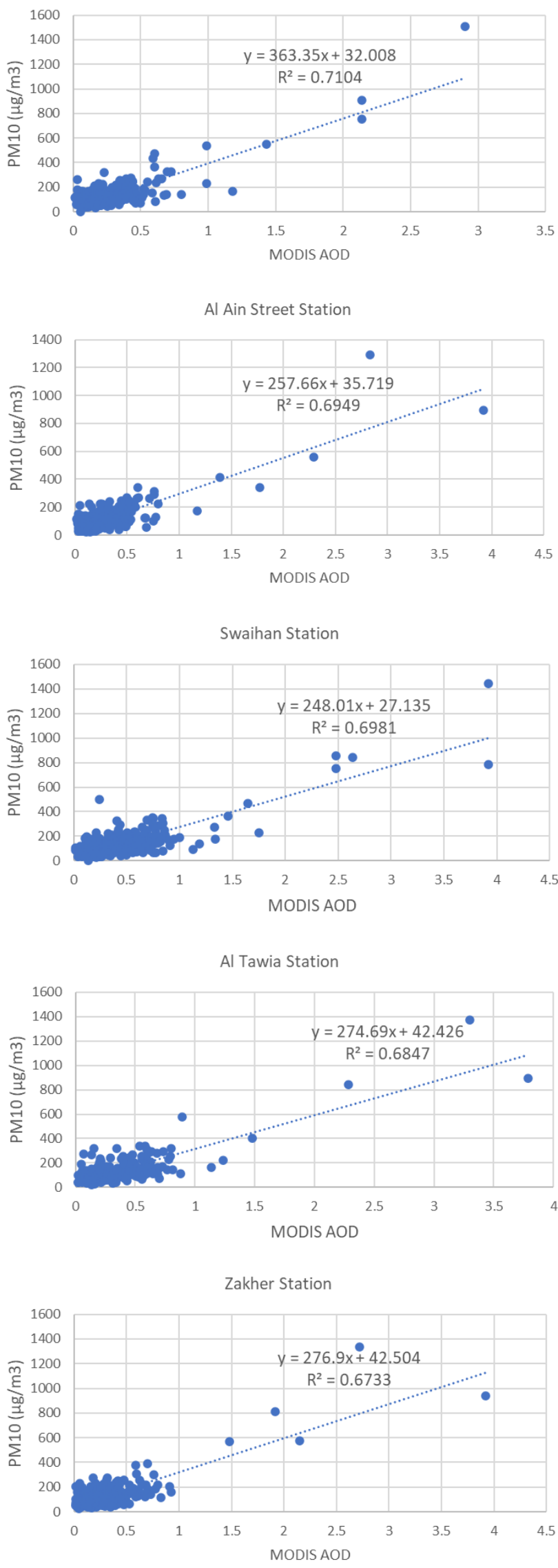

Figure 6. Correlation between MODIS AOD and PM10 for individual air quality monitoring stations.
PM10 measurements from all five stations were then combined and correlated with matching MODIS AOD values. The results are presented in figure 7 that indicates an acceptable level of correlation when using linear regression with a $\mathrm{R}^{2}$ value of 0.75 . Since the whole study area is under similar meteorological and environmental conditions, combining all the monitoring stations to perform the regression did not impact negatively the results. Additionally, it presents a great advantage over using the stations individually as it yields one regression equation that can be used across the whole area.

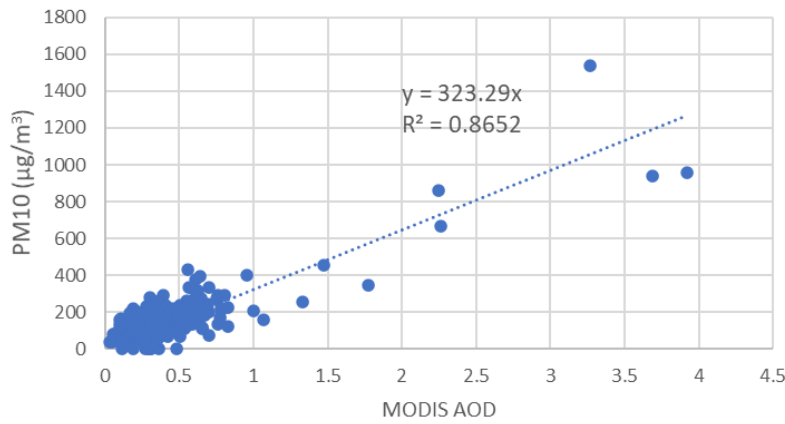

Figure 7. Correlation between MODIS AOD and PM10 for all stations combined.

\subsection{PM10 estimates from MODIS AOD}

The linear regression equation obtained from correlating MODIS AOD and PM10 measurements from all five monitoring stations combined (see figure 7) was used to estimate PM10 over the study area from daily MODIS data. A sample of the results for selected dates is presented in figure 8 .

To evaluate the performance of the PM10 estimation process, AOD values matching the five monitoring stations were used in the model to estimate PM10 at the stations' locations. The predicted PM10 values were then compared to the actual measured values and a mean absolute percentage error (MAPE) was calculated. Using all five stations, the average MAPE was calculated to be $35.9 \%$. This result compares well with other similar studies such as a PM10 estimation study over the Shanxi province in China where an average error of $28.8 \%$ was found to be good enough for subsequent experiments (Hui, 2018).

The approach presented in this study illustrates the potential of using MODIS AOD to predict PM10 over large areas and hence enables more thorough analysis of its spatial variations.

\subsection{Conclusions}

This study presented an approach to estimate PM10 concentrations from MODIS AOD at $550 \mathrm{~nm}$ in the study area. A linear regression model was derived by correlating air quality monitoring stations PM10 data and MODIS MAIAC AOD retrievals. The model was achieved with a reasonable $\mathrm{R}^{2}$ of 0.75 without using additional ancillary data. While the results are considered satisfactory, they can be further improved by integrating meteorological data and segmentation based on land use.

Using remote sensing data to estimate PM10 concentration is promising as it allows to fill gaps where monitoring stations are not present and help better understand the spatial variability of this parameter. 

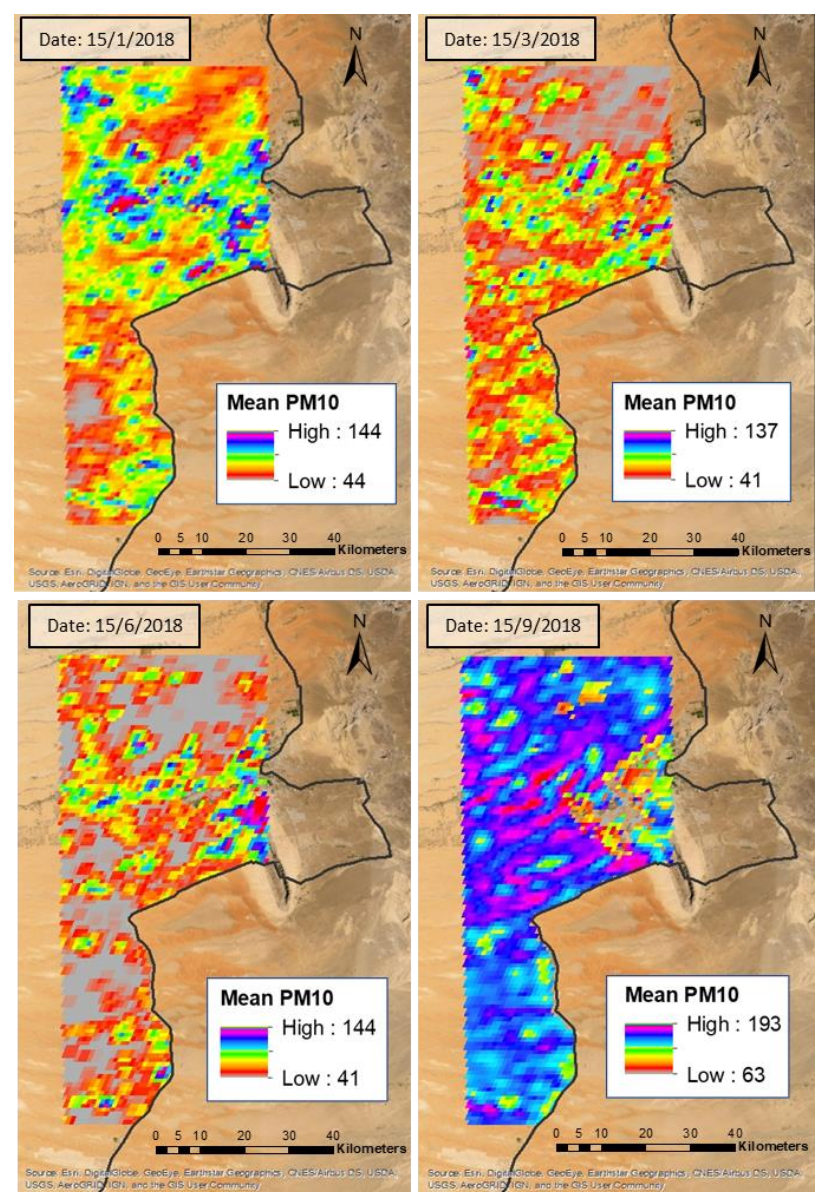

Figure 8. Daily mean PM10 concentration maps of Al Ain city for four different dates in 2018.
Gupta P., Christopher S.A., (2009). Particulate matter air quality assessment using integrated surface, satellite, and meteorological products: 2. A neural network approach. J. Geophys. Res., 114, D20205, doi:10.1029/2008JD011497.

Hui, L., (2018). Estimation of PM10 concentration changes in Shanxi province using MODIS satellite data. IOP Conf. Ser.: Earth Environ. Sci. 199032078.

Koelemeijer R.B.A., Homan C.D., Matthijsen, J., (2006). Comparison of spatial and temporal variations of aerosol optical thickness and particulate matter over Europe. Atmospheric Environment, 40, 5304- 5315.

Liu, Y., C. J. Paciorek, and P. Koutrakis (2009), Estimating regional spatial and temporal variability of PM2.5 concentrations using satellite data,meteorology, and land use information, Environ. Health Perspect., 117, 886-892.

Lyapustin, A., Martonchik, J., Wang, Y., Laszlo, I., and Korkin, S., (2011). Multi-Angle Implementation of Atmospheric Correction (MAIAC): Part 1. Radiative Transfer Basis and Look-Up Tables, J. Geophys. Res., 116, D03210, doi:10.1029/2010JD014985.

Omari, K., A Abuelgasim, K Alhebsi, (2019). Aerosol optical depth retrieval over the city of Abu Dhabi, United Arab Emirates (UAE) using Landsat-8 OLI images, Atmospheric Pollution Research.

Tian J., Chen D., (2010). Spectral, spatial, and temporal sensitivity of correlating MODIS aerosol optical depth with ground-based fine particulate matter (PM2.5) across southern Ontario. Can. J. Remote Sensing, 36, 119-128.

Villeneuve P.J., Goldberg M.S., Krewski D., Burnett R.T., Chen Y., (2002). Fine particulate air pollution and all-cause mortality within the Harward six-cities study:variations in risk by period of exposure. Annals of Epidemiology, 12, 568-576.

\section{REFERENCES}

Chu D.A., Kaufman Y.J., Zibordi G., Chern J.D., Mao J., Li C., Holben B.N., (2003). Global monitoring of air pollution over land from the Earth Observing System-Terra Moderate Resolution Imaging Spectrora-diometer (MODIS), J. Geophys. Res., 108(D21), 4661, doi:10.1029/2002JD003179.

Engel-Cox J.A., Holloman C.H., Coutant B.W., Hoff R.M., (2004). Qualitative and quantitative evaluation of MODIS satellite sensor data for regional and urban scale air quality. Atmos. Environ., 38, 2495-2509.

Gupta P., Christopher S.A., Wang J., Gehrig R., Lee Y.C., Kumar N., (2006). Satellite remote sensing of particulate matter and air quality over global cities. Atmos. Environ., 40, 58805892.

Gupta P., Christopher S.A., (2009). Particulate matter air quality assessment using integrated surface, satellite, and meteorological products: 1. Multiple regression approach. J. Geophys. Res., 114, D14205, doi:10.1029/2008JD011496.

Engel-Cox J A., Hoff R.M., Rogers R., Dimmick F., Rush A.C., 